\title{
Addition of sodium caseinate to skim milk increases nonsedimentable casein and causes significant changes in rennet-induced gelation, heat stability, and ethanol stability
}

\author{
Yingchen Lin, ${ }^{*}$ Alan L. Kelly, $\dagger$ James A. O’Mahony, $\dagger$ and Timothy P. Guinee ${ }^{* 1}$ \\ *Teagasc Food Research Centre Moorepark, Fermoy, Co. Cork, Ireland \\ †School of Food and Nutritional Sciences, University College Cork, Ireland
}

\begin{abstract}
The protein content of skim milk was increased from 3.3 to $4.1 \%$ (wt/wt) by the addition of a blend of skim milk powder and sodium caseinate (NaCas), in which the weight ratio of skim milk powder to NaCas was varied from 0.8:0.0 to 0.0:0.8. Addition of NaCas increased the levels of nonsedimentable casein (from $\sim 6$ to $18 \%$ of total casein) and calcium (from $\sim 36$ to $43 \%$ of total calcium) and reduced the turbidity of the fortified milk, to a degree depending on level of NaCas added. Rennet gelation was adversely affected by the addition of $\mathrm{NaCas}$ at $0.2 \%(\mathrm{wt} / \mathrm{wt})$ and completely inhibited at $\mathrm{NaCas} \geq 0.4 \%$ (wt/wt). Rennet-induced hydrolysis was not affected by added NaCas. The proportion of total casein that was nonsedimentable on centrifugation $\left(3,000 \times g, 1 \mathrm{~h}, 25^{\circ} \mathrm{C}\right)$ of the rennet-treated milk after incubation for $1 \mathrm{~h}$ at $31^{\circ} \mathrm{C}$ increased significantly on addition of NaCas at $\geq 0.4 \%$ (wt/wt). Heat stability in the $\mathrm{pH}$ range 6.7 to 7.2 and ethanol stability at $\mathrm{pH} 6.4$ were enhanced by the addition of NaCas. It is suggested that the negative effect of NaCas on rennet gelation is due to the increase in nonsedimentable casein, which upon hydrolysis by chymosin forms into small nonsedimentable particles that physically come between, and impede the aggregation of, rennet-altered para-casein micelles, and thereby inhibit the development of a gel network.
\end{abstract}

Key words: milk, protein fortification, dairy ingredients, processing characteristics

\section{INTRODUCTION}

Milk protein powders are extensively used as ingredients because of their techno-functional and nutritional properties. Applications include their use as ingredients in high-protein beverages, nutritional beverages (e.g.,

Received July 6, 2016.

Accepted November 1, 2016.

${ }^{1}$ Corresponding author: tim.guinee@teagasc.ie for children), formulated and consumer foods, and recombined milks for the preparation of cheeses and fermented milk products (Gilles and Lawrence, 1982; McSweeney et al., 2013; Lagrange et al., 2015). The techno-functionalities required vary considerably according to application and may include water binding capacity, emulsification, heat stability, ability to undergo gelation (e.g., on heating, acidification, or rennet treatment), and structure formation. In many of these applications, milk proteins are exposed to various unit operations (including acidification, heating, rennet treatment, dehydration) and environments (e.g., food matrices differencing in solvent quality) that challenge their stability and functionality (Agarwal et al., 2015). The different functional requirements during food processing and formulation are met through the supply of a range of ingredients differing in protein type and content, extent of protein denaturation, degree of mineralization, and composition.

Skim milk powder (SMP) and sodium caseinate (NaCas) are widely used ingredients. They differ in method of manufacture, protein structure, and degree of mineralization. The manufacture of NaCas involves $\mathrm{pH}$ adjustment of the milk to the isoelectric point, precipitation of the casein and whey separation, washing and concentration, addition of sodium hydroxide to readjust the $\mathrm{pH}$ of the casein from $\sim 6.8$ to 7.0 , and drying (Carr and Golding, 2016). During acidification, essentially all of the colloidal calcium phosphate, which contributes to the self-assembly of the casein into micelles, is dissolved, resulting in the dissociation of the casein micelles into smaller particles referred to as submicelles. Analysis of $\mathrm{NaCas}$ indicates significantly lower ratios of calcium- and phosphorus-to-casein compared with native casein in milk and the occurrence of the casein in the form of particles ( $\sim 10 \mathrm{~nm}$ compared with $\sim 150$ to $200 \mathrm{~nm}$ in the native casein micelle; O'Connell and Fox, 2000). In contrast, the structure of the casein and its degree of mineralization in SMP is not affected by the method of manufacture, which involves evaporation and drying of the milk. 
These differences in casein structure and degree of mineralization are likely to affect rennet gelation, a critical parameter in the manufacture of cheese. Gaygadzhiev et al. (2012) found that the rennet-induced gelation of milk was impaired by the addition of $0.05 \%$ (wt/wt) NaCas and completely inhibited at a level $\geq 0.2 \%$ (wt/wt). The authors suggested the inhibitory effect of NaCas was likely due to the adsorption of the rennet-hydrolyzed NaCas to the surface of the paracasein micelle and the concomitant increase in steric and electrostatic repulsion, which impeded aggregation of the latter. Subsequently, Nair and Corredig (2015) found that the addition of $0.6 \%$ (wt/wt) NaCas to milk concentrated 3-fold had no effect on rennet gelation when the milk had been concentrated by ultrafiltration, but severely impeded gelation when the milk had been concentrated quiescently by osmotic concentration using polyethylene glycol. The dependence on the method of concentration was attributed to potential differences in the extent of rearrangement of the native micelles during concentration, which affected their interaction with the added NaCas and the degrees to which it became adsorbed at the surface of, or incorporated into, the micelle. Thomar and Nicolai (2015) reported that the addition of $\mathrm{NaCas}$ to an aqueous dispersion of native phosphocasein powder (NPC, $1.5 \%$, wt/wt, protein) promoted dissociation of casein, $\mathrm{Ca}$, and $\mathrm{P}$ from the micelle to a degree that increased with weight fraction of added NaCas.

The heat stability of dairy proteins is important in products such as UHT milk, infant milk formula, and coffee whiteners. Consequently, heat stability of milk and the factors affecting it have been extensively studied (Huppertz, 2016). Comparatively, little information is available on the effect of adding NaCas to milk on the heat stability. Cho and Singh (1999) observed an increase in the heat stability $\left(140^{\circ} \mathrm{C}\right)$ of recombined milk, formulated by blending an aqueous milk fat emulsion and reconstituted SMP, over the $\mathrm{pH}$ range 6.4 to 7.1, when the emulsion was stabilized using NaCas instead of SMP or whey protein concentrate.

Cream liqueurs are formulated mainly from cream (33-40\%, wt/wt), ethanol ( $12-15 \% \mathrm{vol} / \mathrm{vol})$, sucrose $(\sim 18.5 \%$, wt/wt), milk protein (typically $\sim 3.5 \%$, wt/ wt, NaCas), and water ( 25-30\%, wt/wt; Muir, 1988). The ethanol stability of NaCas is of particular relevance in emulsion stabilization and control of storage-related flocculation, thickening, or gelation. O'Kennedy et al. (2001) reported that the ethanol stability of a 3\% (wt/ wt) aqueous dispersion of $\mathrm{NaCas}$ depended on $\mathrm{pH}$ and ionic strength.

The principal objective of the current study was to investigate the effect of incrementally increasing NaCas from 0 to $0.8 \%$ (wt/wt) on the rennet gelation, heat
Table 1. Composition of dairy ingredients used for fortifying the protein content of skim milk ${ }^{1}$

\begin{tabular}{lcc}
\hline & \multicolumn{2}{c}{ Ingredient } \\
\cline { 2 - 3 } Composition $^{2}$ & SMP & NaCas \\
\hline Total protein (\%,wt/wt) & 36.4 & 87.9 \\
Casein (\% TP) & 82.8 & 97.0 \\
Whey protein (\% TP) & 11.2 & 1.2 \\
Lactose (\%, wt/wt) & 46.35 & 1.27 \\
Ca (mg/100 g) & 1,295 & 193 \\
$\mathrm{P}(\mathrm{mg} / 100 \mathrm{~g})$ & 913 & 687 \\
\hline
\end{tabular}

${ }^{1} \mathrm{SMP}=$ low heat skim milk powder; NaCas $=$ sodium caseinate. ${ }^{2} \mathrm{TP}=$ total protein.

stability, and ethanol stability of fortified milk (4.1\%, wt/wt, protein) prepared by adding a blend of SMP and NaCas to skim milk (3.3\%, wt/wt, protein) in which the weight ratio of protein from SMP-to-NaCas was varied from 0.8:0.0 to 0.0:0.8. A secondary objective was to relate the effects of $\mathrm{NaCas}$ on the above properties to changes in the partition of protein and minerals between the sedimentable and nonsedimentable phases obtained on ultracentrifugation of the fortified milk at $100,000 \times g$.

\section{MATERIALS AND METHODS}

\section{Milk Protein Ingredients}

Milk protein ingredients used included extra low-heat SMP ( $<4 \%$ of total whey protein denatured) and $\mathrm{Na}-$ Cas. The respective levels of total protein, casein, whey protein, lactose, $\mathrm{Ca}$, and $\mathrm{P}$ contents of the SMP and NaCas are shown in Table 1.

\section{Preparation of Milk}

A skim milk base $(3.3 \%$, wt/wt, protein) was prepared from reconstituted SMP, rather than using fresh skim milk, to ensure a compositionally consistent starting material and to avoid the potential confounding effects of seasonal changes in milk quality and composition on the measured characteristics, during replicate trials. The skim milk base was prepared by dispersing the SMP in distilled water at $50^{\circ} \mathrm{C}$ while shearing at 6,300 rpm for 5 min using a high-shear mixer (Silverson model L4RT, Silverson, Chesham, UK) until the powder was visually dispersed. The sample was then placed at $4^{\circ} \mathrm{C}$ for $22 \mathrm{~h}$ to allow for hydration of the protein. The preparation of the fortified milk $(4.1 \%$, wt/wt, protein) involved adding the blend of SMP and NaCas powders to the base skim milk in sufficient quantities to increase the protein content from 3.3 to $4.1 \%$ (wt/wt). The ratio of protein derived from the SMP to protein 
from the NaCas during fortification was varied as follows: $0.0: 0.8,0.2: 0.6,0.4: 0.4,0.5: 0.3,0.6: 0.2,0.7: 0.1$, and 0.8:0.0. Following addition of SMP or NaCas, the temperature was maintained at $50^{\circ} \mathrm{C}$ while shearing for a further $20 \mathrm{~min}$. Sodium azide was added at a level of $0.02 \%$ (wt/vol) to all milk samples before cooling for preservation purposes.

The cold aging effect of holding milk samples at $4^{\circ} \mathrm{C}$ was reversed by incubating the milk at $40^{\circ} \mathrm{C}$ for $30 \mathrm{~min}$ before all assays (Fox, 1969).

\section{Preparation of Milk Ultracentrifugate}

Milk ultracentrifugate was prepared by centrifugation of milk at $100,000 \times g$ for $1 \mathrm{~h}$ at $25^{\circ} \mathrm{C}$, and decantation of the supernatant through glass wool.

\section{Composition of Milk and Milk Ultracentrifugate}

The fortified milk (4.1\%, wt/wt, protein) was analyzed for fat and TS using CEM SMART Trac II (CEM, Matthews, NC), total protein by Kjeldahl (International Dairy Federation, IDF, 2001a), and lactose by the FOSS MilkoScan FT+ (N. Foss Electric A/S, Hillerød, Denmark). Calcium content in milk and ultracentrifugate was measured by ashing at $550^{\circ} \mathrm{C}$ followed by atomic absorption spectrometry (AA240, Varian AA, Varian Inc., Palo Alto, CA) at $422.7 \mathrm{~nm}$ (IDF, 2007); P was assayed by ashing at $550^{\circ} \mathrm{C}$ followed by molecular absorption spectrometry (GenesysTM5, Milton Roy, PA) at $820 \mathrm{~nm}$ (IDF, 2006), respectively. Total N, noncasein nitrogen, and the NPN in milk and ultracentrifugate were determined using standard IDF methods (IDF, 2001a,b). The sensION+ 9660C Calcium Combination Ion Selective Electrode (Hach Lange, Barcelona, Spain) was used to measure the concentration of ionic calcium $\left(\left[\mathrm{Ca}^{2+}\right]\right)$. The electrode was calibrated using calcium chloride solutions with different concentration of $\left[\mathrm{Ca}^{2+}\right]$ ranging from 0.5 to $5 \mathrm{mM}$. Potassium chloride $(3 \mathrm{M})$ was added to the milk at a level of $1 \%(\mathrm{vol} / \mathrm{vol})$ and the milk was assayed immediately for $\mathrm{Ca}^{2+}$ concentration while stirring.

Protein profile was determined by reversed-phase HPLC (Agilent 1200 series, Agilent Technologies, Santa Clara, CA) using a 300 SB-C18 RP Poroshell column (Agilent Technologies), according to the method of Visser et al. (1991).

\section{Turbidity ( $T$ )}

Fortified milk was diluted 1:10 using milk permeate prepared by laboratory-scale UF of skim milk (NovaSet-LS cassette, $10 \mathrm{kDa}, 0.1 \mathrm{~m}^{2}$, ProStream modified polyethersulfone membrane, TangenX Technology Cor- poration, Shrewsbury, MA). The diluted sample was agitated gently and the turbidity was measured at 860 nm using a 2100N Turbidimeter (Hach Lange GmbH, Willstätterstraße, Germany).

\section{Casein Micelle Size}

Fortified milk was diluted 1:10 (vol/vol) in simulated milk ultrafiltrate, prepared according to Jenness and Koops (1962). The casein micelle size was then measured using the Malvern Zetasizer Nanoseries Nano-ZS (Malvern Instruments Ltd., Malvern, UK) with a backscatter angle of $173^{\circ}$ at $25^{\circ} \mathrm{C}$. The mean average size (zaverage) was measured using an intensity distribution.

\section{Rennet Gelation}

Milk was adjusted to $\mathrm{pH} 6.55$ and tempered to $31^{\circ} \mathrm{C}$. Chymosin (single strength Chy-Max plus, 200 international milk clotting units/mL; Chr. Hansen, Hørsholm, Denmark) was diluted 1 in 20 with distilled water, and added at a level of $421 \mu \mathrm{L} / 100 \mathrm{~mL}$ to the milk sample and mixed for $30 \mathrm{~s}$; this level of rennet addition equates to $0.21 \mathrm{~mL}$ of Chy-Max plus per liter of milk with $4.1 \%$ protein. The storage modulus $\left(\mathbf{G}^{\prime}\right)$ was measured dynamically as a function of time over $1 \mathrm{~h}$ at a strain of 0.025 and a frequency of $1 \mathrm{~Hz}$ in a controlled stress rheometer (Carri-Med, type $\mathrm{CSL}^{2}{ }_{500}$, TA Instruments, New Castle, DE; Guinee et al., 2006). The following parameters were calculated from the resultant $G^{\prime} / t$ curve: gelation time, defined as the time for $\mathrm{G}^{\prime}$ to reach a value of $\geq 0.2 \mathrm{~Pa}$; maximum curd firming rate, the maximum slope of the curve; and gel firmness at $60 \mathrm{~min}$ after rennet addition $\left(\mathbf{G}^{\prime}{ }_{60}\right)$.

The level of proteolysis of $\kappa$-CN in the rennet-treated milk at $\mathrm{pH} 6.55$ was determined by measuring the change in the level of total $\mathrm{N}$ soluble in $12 \%$, wt/vol, trichloroacetic acid (TCA) at different time intervals during the 60-min incubation period (Hindle and Wheelock, 1970).

Following incubation for $60 \mathrm{~min}$ at $31^{\circ} \mathrm{C}$, the rennet-treated milk was centrifuged at different $g$ force $(3,000-100,000)$ for $1 \mathrm{~h}$ at $25^{\circ} \mathrm{C}$ to determine if casein which was nonsedimentable in the milk before rennet treatment sedimented following hydrolysis with chymosin. The resultant supernatant was filtered (Whatman 1001-185; Whatman International Ltd., Maidstone, UK). The resultant whey (serum) was analyzed for protein, $\mathrm{Ca}$, and $\mathrm{P}$, as described above for milk.

\section{Heat Stability and Ethanol Stability}

Milk samples were adjusted to different $\mathrm{pH}$ values in the range from 6.2 to 7.2 (0.1 pH unit increments) at 
room temperature using $0.1 \mathrm{~N} \mathrm{HCl}$ or $\mathrm{NaOH}$. A subsample $(3.4 \mathrm{~g})$ was placed in a 4 -mL heat-resistant tube (120 $\mathrm{mm}$ tube length, $10 \mathrm{~mm}$ outer radius, $7 \mathrm{~mm}$ inner radius; Hettich Benelux BV, Geldermalsen, the Netherlands), which was capped with a rubber bung and placed and secured in a metal rack. The loaded rack was placed in the temperature-controlled oil bath (Hettich ESP oilbaths; Hettich Benelux BV) at $140^{\circ} \mathrm{C}$ and rocked gently at a constant frequency (7 oscillations/ min). The time for visual flocculation of the milk on the walls of the tube was recorded as the heat stability (O'Connell and Fox, 2000). The analysis at each pH was performed in duplicate and the mean values for each $\mathrm{pH}$ were used to construct a heat stability $/ \mathrm{pH}$ curve.

The ethanol stability of a subsample of each milk, adjusted to a $\mathrm{pH}$ value in the range 6.2 to 7.0 , was measured as the concentration of ethanol required for visual flocculation on blending the milk with ethanol solutions of varying strength (30-98\% ethanol, vol/vol) at a volume ratio of 1:4.8 (Horne and Muir, 1990).

\section{Statistical Analysis}

Duplicate batches of each treatment milk, containing different levels of added sodium caseinate, were prepared on separate occasions. The data were analyzed using a randomized complete block design incorporating the 7 different milk treatments (fortified milk with different proportions of SMP and NaCas) and 2 blocks (replicate trials). The effect of treatment was determined by applying ANOVA using the general linear model procedure of SAS 9.3 (SAS Institute Inc., 2011). Tukey's multiple-comparison test was used as a guide for paired comparisons of the treatment means and the level of significance was determined at $P<0.05$. The data were also analyzed by linear regression to establish potential correlations between measured parameters.

\section{RESULTS}

\section{Composition of Milk and Milk Ultracentrifugate}

Increasing NaCas, as a proportion of added protein (i.e., reducing the ratio of SMP:NaCas), resulted in lower levels of whey protein (as \% total protein), lactose, $\mathrm{Ca},\left[\mathrm{Ca}^{2+}\right]$, and $\mathrm{P}(P<0.05$; Table 2$)$; moreover, when added NaCas was increased from 0 (\%, wt/wt) to $\geq 0.4 \%$ (wt/wt), casein (as a $\%$ of total protein) increased significantly. This trend is consistent with the lower levels of lactose, whey protein, $\mathrm{Ca}$, and $\mathrm{P}$ in NaCas compared with SMP.

The concentration of casein in the ultracentrifugate (nonsedimentable casein) increased significantly with level of added NaCas (Table 3 ), from $\sim 6.1 \%$ of total casein, or $\sim 0.19 \%$ (wt/wt), in fortified milk without NaCas to $17.9 \%$ total casein, or $0.61 \%$ (wt/wt), in fortified milk with $0.8 \%$ (wt/wt) added NaCas. The level of casein in the ultracentrifugate of the fortified milk without added NaCas was similar to that of control

Table 2. Compositional and physico-chemical characteristics of skim milk fortified to $4.1 \%$ protein (wt/wt) using a blend of sodium caseinate and skim milk powder ${ }^{1,2}$

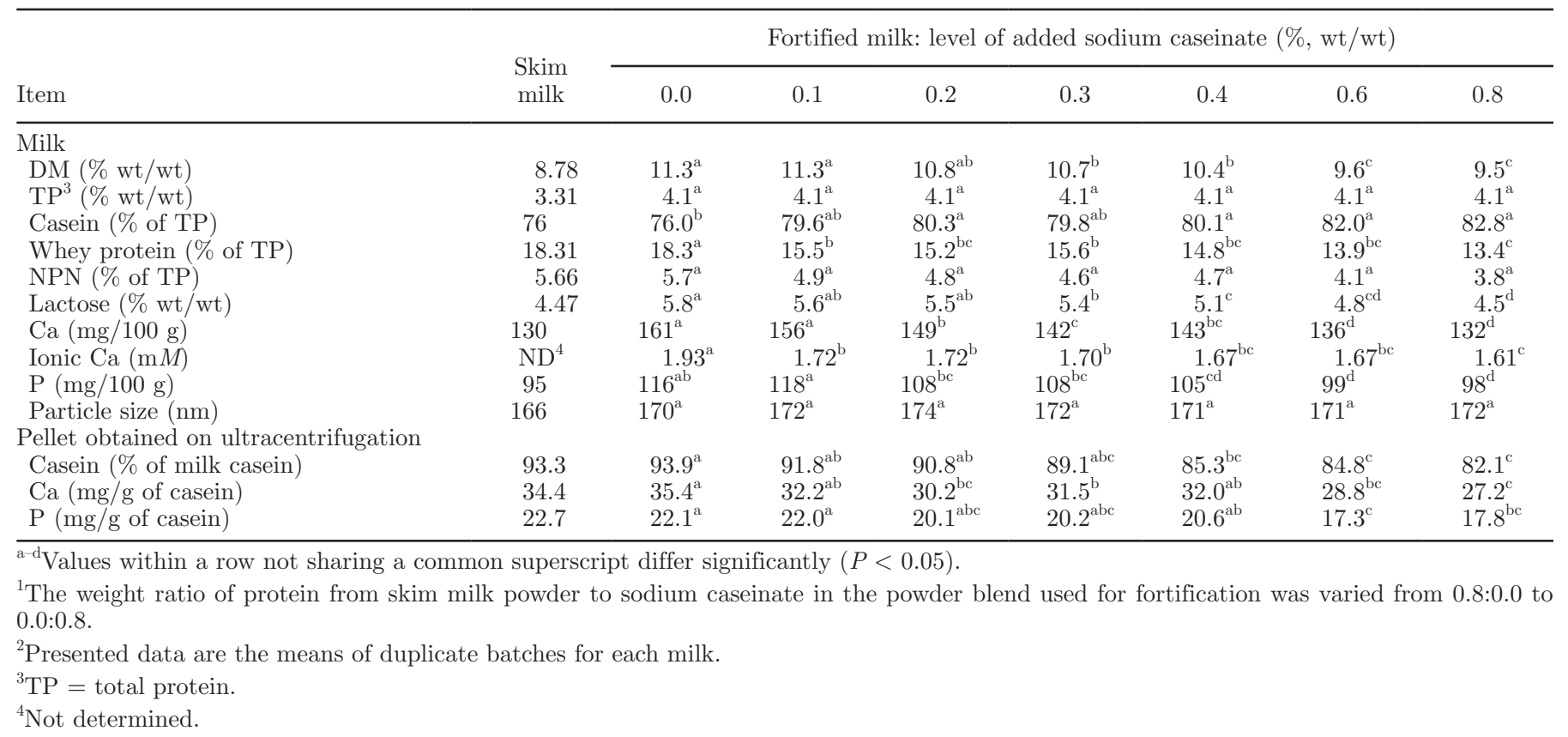


Table 3. Composition of milk ultracentrifugate obtained on centrifugation of fortified milk (4.1\%, wt/wt, protein) with different levels of added sodium caseinate ${ }^{1,2}$

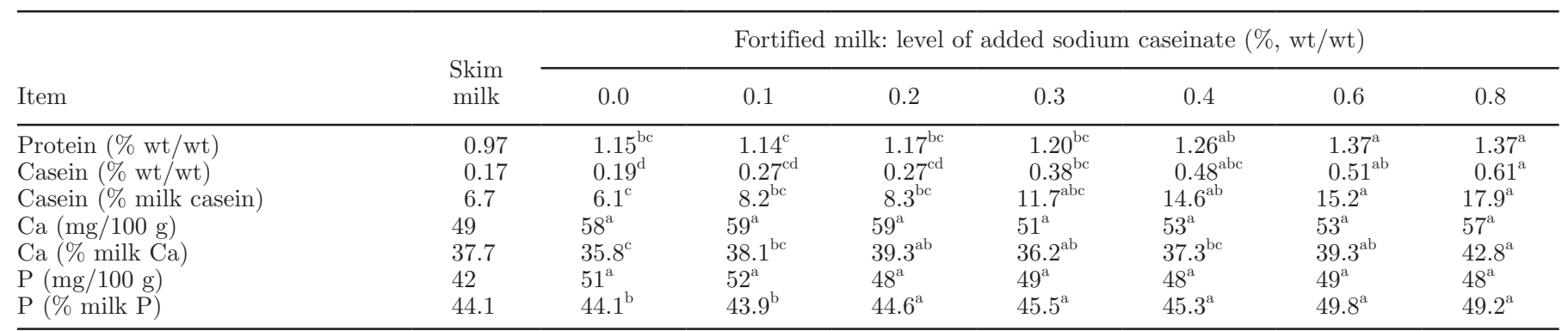

${ }^{\mathrm{a}-\mathrm{d}}$ Values within a row not sharing a common superscript letter differ significantly $(P<0.05)$.

${ }^{1}$ The weight ratio of protein from skim milk powder to sodium caseinate in the powder blend used for fortification was varied from 0.8:0.0 to 0.0:0.8. Ultracentrifugate was obtained by centrifugation at $100,000 \times g$ at $25^{\circ} \mathrm{C}$ for $1 \mathrm{~h}$.

${ }^{2}$ Presented data are the means of duplicate batches for each milk.

(nonfortified) skim milk (Table 3). The proportions of individual caseins in the milk ultracentrifugate, expressed as \% of the corresponding casein in milk, changed little on increasing added NaCas from 0.0 to $0.4 \%$ (wt/wt) but increased significantly on further increasing NaCas from 0.4 to $0.8 \%$ (wt/wt; Figure $1 \mathrm{~A}$ ). At $0.8 \%$ (wt/wt) added NaCas, the proportions of individual caseins in the serum, expressed as a $\%$ of the corresponding level in milk, were in the following order: $\kappa$-CN $(39 \%)>\beta-\mathrm{CN}(28 \%)>\alpha_{\mathrm{S}^{-}} \mathrm{CN}(17 \%)>$ $\alpha_{S_{2}}$ CN (16\%). Expressed as \% of total casein in the ultracentrifugate, $\kappa-\mathrm{CN}$ and $\alpha_{\mathrm{S} 1}-\mathrm{CN}$ changed with level of added NaCas, with the former decreasing and the latter increasing, respectively, at NaCas $\geq 0.3 \%$ (wt/wt; $P<$ $0.05)$. The proportions of, $\kappa-\mathrm{CN}, \beta-\mathrm{CN}, \alpha_{\mathrm{S} 1}-\mathrm{CN}$, and $\alpha_{\mathrm{S}_{2}} \mathrm{CN}$ accounted for $29,40,24$, and $7 \%$, respectively, at $0.8 \%$ (wt/wt) NaCas (Figure 1B).

\section{Particle Size and Turbidity}

All milk samples showed a mono-modal particle size distribution and z-average of $\sim 170 \mathrm{~nm}$ (Table 2), which is within the range reported by others [i.e., 130-200 nm (Holt and Muir, 1978; O'Connell and Fox, 2000; Glantz et al., 2010)].

Turbidity of the fortified milk, diluted (1:10) in ultrafiltered milk permeate at $860 \mathrm{~nm}$, decreased linearly from 1,537 to 1,360 nephelometric turbidity units with increasing fraction of NaCas from 0 to $0.8 \%$ (wt/wt; Figure 2).

\section{Rennet Gelation Properties}

The addition of NaCas adversely affected the rennet gelation properties of the fortified milk, as reflected by a significant increase in the gelation time and reductions in $\mathrm{G}_{60}^{\prime}$ and max curd firming rate (Figure 3 ). The value of $\mathrm{G}_{60}^{\prime}$ decreased linearly $(P<0.05)$ as the level of added NaCas was increased from 0.0 to $0.3 \%$ (wt/ wt) and the milk did not gel when NaCas was added at levels $\geq 0.4 \%$ (wt/wt; Figure 3 ).

\section{Proteolysis During Rennet Gelation}

The level of $12 \%$ (wt/vol) TCA-soluble N (SN) has been used as index of the degree of hydrolysis of $\kappa$-CN by the coagulant, and the formation of the resultant caseino-macropeptide, during rennet-induced gelation of milk (Hindle and Wheelock, 1970).

Rennet-treated milk with different levels of added NaCas was examined for the rate of formation of $12 \%$ (wt/vol) TCA-SN during incubation at $31^{\circ} \mathrm{C}$ to establish if the adverse effect of added NaCas at $\geq 0.3 \%$ (wt/ wt) on rennet-induced gelation was due to inhibition of the primary-stage enzymatic hydrolysis of $\kappa-\mathrm{CN}$, inhibition of the secondary-stage aggregation of the chymosin-altered micelles into a gel, or a combination of both. $12 \%$ (wt/vol) TCA-SN increased with incubation to $40 \mathrm{~min}$, after which levels plateaued. The mean increase in $12 \%$ (wt/vol) TCA-SN was $\sim 6.9 \mathrm{mg} / 100 \mathrm{~g}$ of milk after 40 min and was not significantly affected by level of added NaCas (Figure 4).

\section{Appearance and Composition of Whey (Serum) from Rennet-Treated Milk Samples}

The whey phase obtained on centrifugation $(3,000$ $\times g)$ of the rennet-treated milk obtained at $1 \mathrm{~h}$ after rennet addition (when the fortified milk without NaCas had formed a very strong gel, $\sim 120 \mathrm{~Pa}$ ) became progressively milky when the level of added NaCas was increased to $\geq 0.4 \%$ (wt/wt); essentially, the rennettreated milk was similar in appearance and consistency (liquid) to the milk without added rennet. Simultaneously, soluble casein, Ca, and P (as \% of total casein, $\mathrm{Ca}$, and $\mathrm{P}$, respectively) increased significantly (Figure 

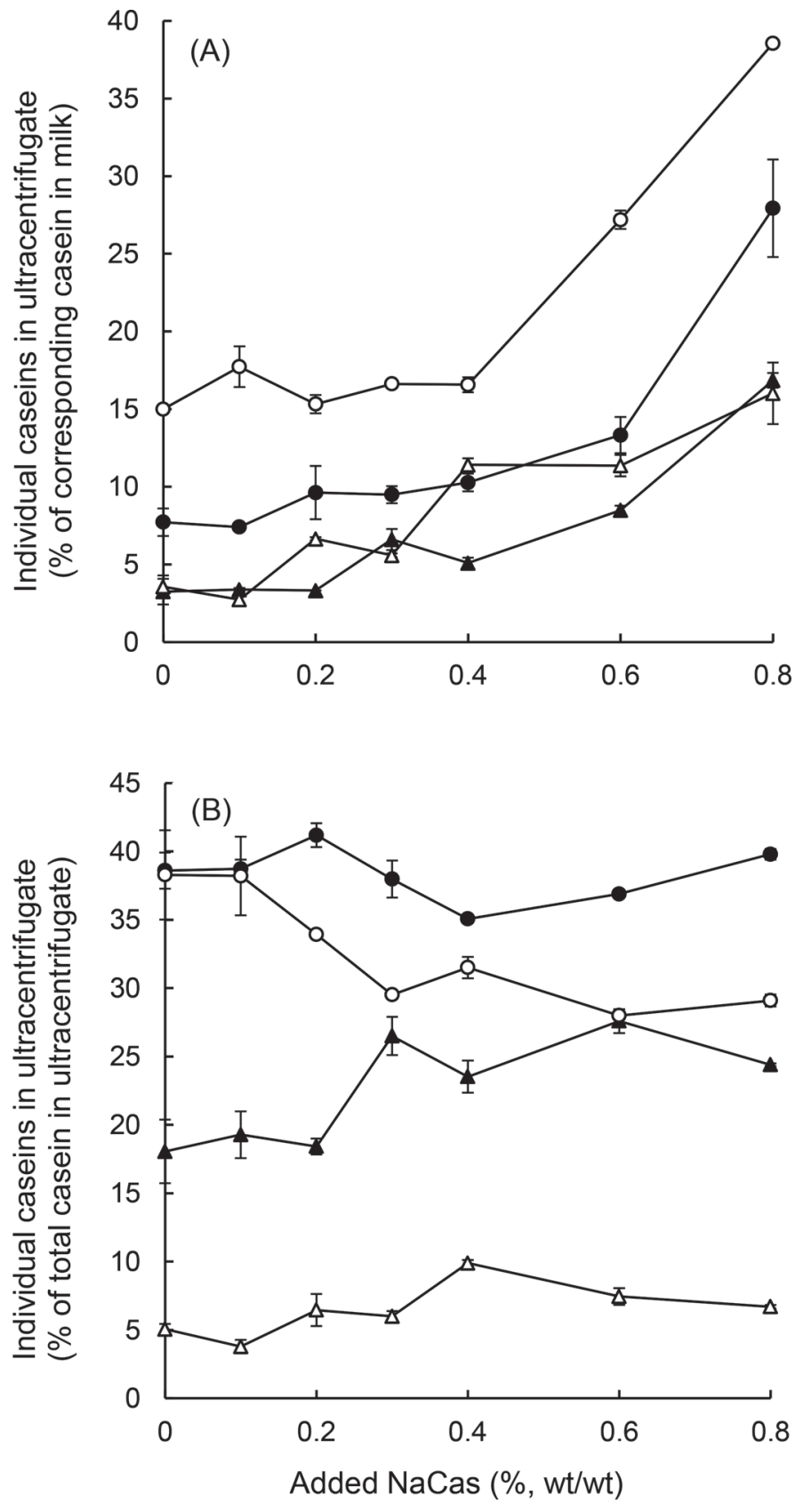

Figure 1. Effect of level of added sodium caseinate in fortified milk (4.1\%, wt/wt, protein) on the concentration of individual caseins in milk ultracentrifugate, expressed as \% of the corresponding casein in milk (A) or as \% of total casein in ultracentrifugate (B): $\alpha_{\mathrm{S1}^{-}} \mathrm{CN}(\boldsymbol{\Lambda})$, $\alpha_{\mathrm{S}_{2}}-\mathrm{CN}(\Delta), \beta-\mathrm{CN}(\bullet)$, and $\kappa-\mathrm{CN}(\bigcirc)$. Presented data are the means of duplicate batches of each treatment milk; error bars show SD of the mean.

5A). Hence, despite similar levels of chymosin-induced proteolysis of the casein at all levels of NaCas addition, the casein remained largely soluble at $3,000 \times g$ when the level of added $\mathrm{NaCas}$ was $\geq 0.4 \%$ (wt/wt). However, the level of soluble casein decreased sharply $(P<0.05)$

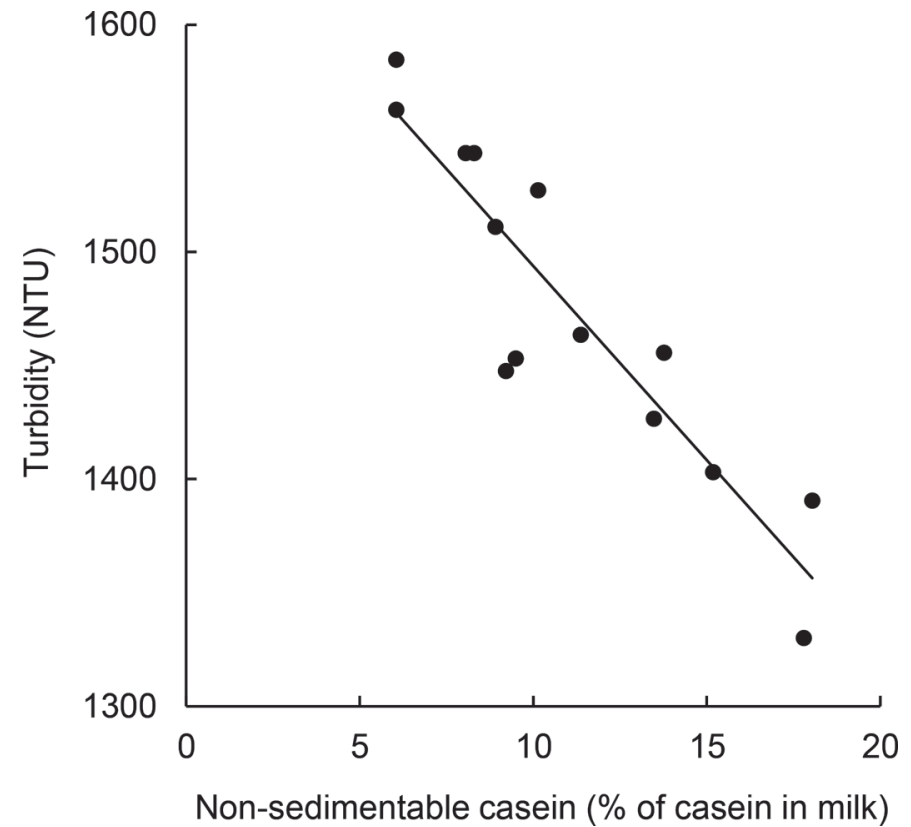

Figure 2. Relationship between turbidity (in nephelometric turbidity units, NTU) and nonsedimentable casein in fortified milk containing 0 to $0.8 \%$ (wt/wt) added sodium caseinate (NaCas; see Table 2 for details). Presented data show values of duplicate batches of 7 fortified milk samples with added NaCas ranging from 0 to $0.8 \%$ (wt/wt).

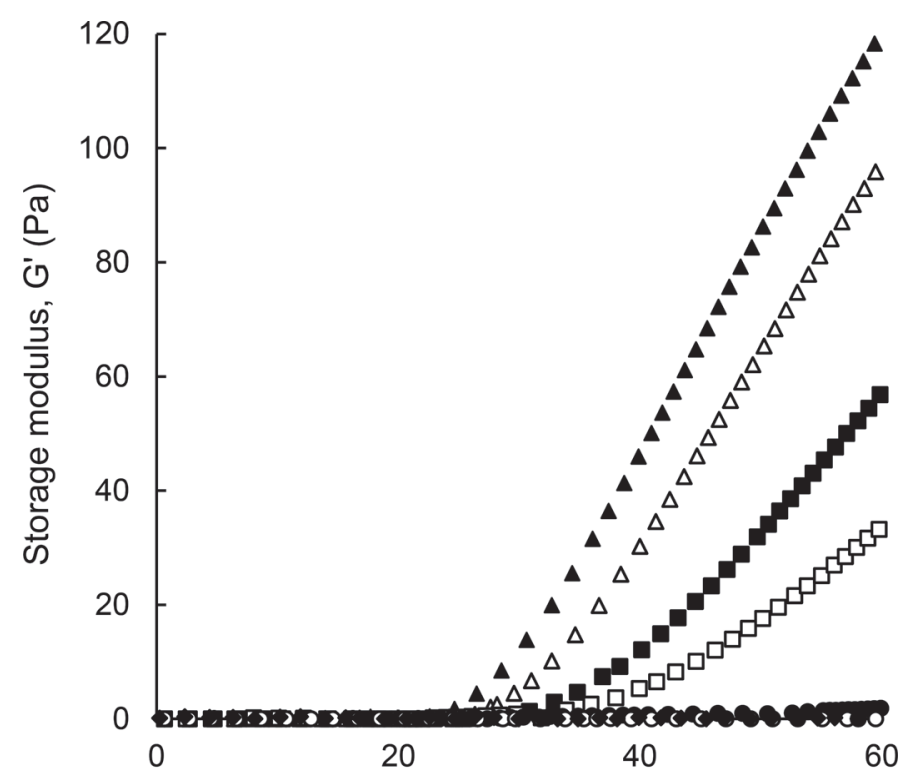

Time from rennet addition ( $\min )$

Figure 3. Development of storage modulus, $\mathrm{G}^{\prime}$, in rennet-treated fortified milk $(4.1 \%$, wt/wt, protein) containing different levels $(\%$, wt/wt) of added sodium caseinate: $0(\mathbf{\Delta}), 0.1(\Delta), 0.2(\boldsymbol{\square}), 0.3(\square), 0.4$ $(\bullet), 0.6(\bigcirc)$, or $0.8(\bullet)$. 
with centrifugation force in the range 3,000 to 100,000 $\times g$, but still remained high in the milk with $0.8 \%$ (wt/ wt) $\mathrm{NaCas}$ at $\leq 30,000 \times g($ Figure $5 \mathrm{~B})$.

\section{Heat Stability and Ethanol Stability}

Increasing the level of NaCas added to the milk did not affect the heat stability profile, which for all milk treatments was type A with a maximum heat coagulation time at $\mathrm{pH} 6.6$ and a minimum at $\mathrm{pH} 6.8$ to 7.0. However, increasing added NaCas to $\geq 0.2 \%$ (wt/wt) coincided with a significant reduction in the maximum stability ( $\mathrm{pH}$ 6.6), an increase in the heat stability at $\mathrm{pH} 6.7$ to 7.2 , a narrowing of the minimum stability $\mathrm{pH}$ zone, and a shift in the $\mathrm{pH}$ of minimum heat stability to lower $\mathrm{pH}$ (Figure 6A). The increase in heat stability was most pronounced at $\mathrm{pH} 7.0$ and 7.1 , and increased progressively with level of added NaCas.

The ethanol stability of all milk treatments increased with $\mathrm{pH}$ from 6.2 to 7.0. Ethanol stability at $\mathrm{pH}$ 6.4, 6.6, and 6.8 increased significantly with level of added NaCas. This effect was most pronounced at $\mathrm{pH} 6.4$ (Figure 7A) where ethanol stability was positively cor- related with nonsedimentable casein (as a proportion of total casein; Figure 7B).

\section{DISCUSSION}

The current study focused on the compositional and stability characteristics of fortified milk $(4.1 \%$, wt/wt, protein) prepared by increasing the protein content of skim milk from 3.3 to $4.1 \%$ using a blend of SMP and $\mathrm{NaCas}$, in which the weight ratio of protein from SMPto-NaCas was varied from 0.0:0.8 to 0.8:0.0. Increasing added NaCas led to a significant increase in nonsedimentable casein, from $\sim 0.19$ to $0.61 \%$ (wt/wt), and a change in the proportion of individual caseins comprising the nonsedimentable casein. $\kappa$-Casein and $\alpha_{\mathrm{S} 1}-\mathrm{CN}$, as proportions of the nonsedimentable casein, decreased $(P<0.05)$ and increased $(P<0.05)$, respectively, as the level of added NaCas was increased from 0.4 to $0.8 \%$ (wt/wt). Added NaCas also increased the proportions of nonsedimentable $\mathrm{Ca}$ and $\mathrm{P}(P<0.05)$. Nevertheless, the mean particle size (z-average) and the area of the size intensity peak in the protein-fortified milk did not change with level of NaCas. Likewise, Gaygadzhiev et al.
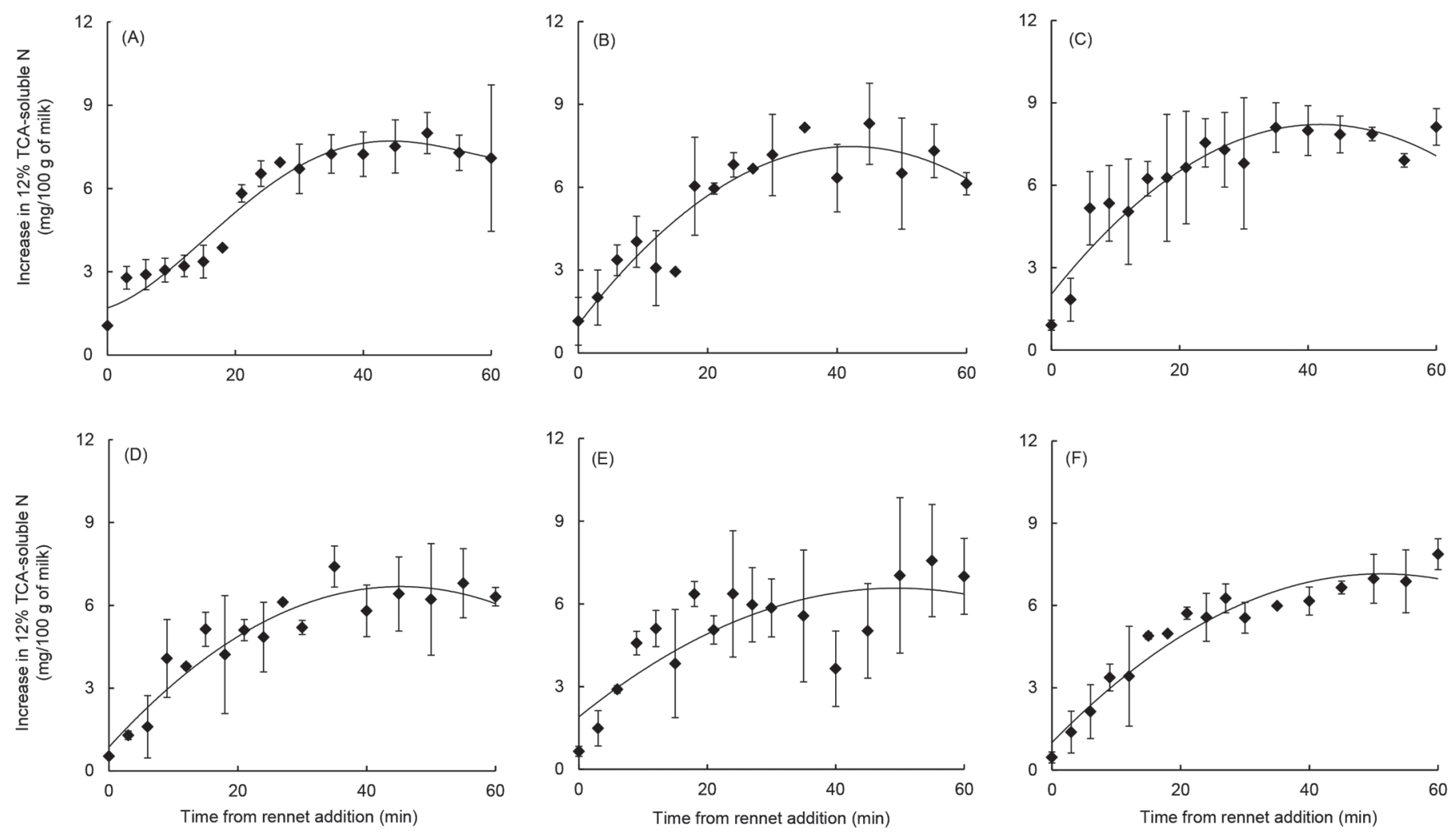

Figure 4. Increase in level of $12 \%$ (wt/vol) trichloroacetic acid (TCA)-soluble $\mathrm{N}(\mathrm{mg} / 100 \mathrm{~g}$ of milk) in rennet-treated fortified milk (4.1\%, wt/wt, protein) containing different levels (\%, wt/wt) of added sodium caseinate: 0 (A), 0.1 (B), 0.2 (C), 0.4 (D), 0.6 (E), or 0.8 (F). Presented data are the means of duplicate batches of each fortified milk; error bars show SD of the mean. 
(2012) found that the addition of $0.1 \%$ (wt/wt) NaCas to skim milk did not affect the apparent diameter of the casein micelle, as measured using dynamic light scattering. This trend suggests that nonsedimentable casein is essentially nonparticulate. In contrast, the turbidity decreased significantly as the level of added $\mathrm{NaCas}$ was increased, reflecting a reduction in the intensity of light
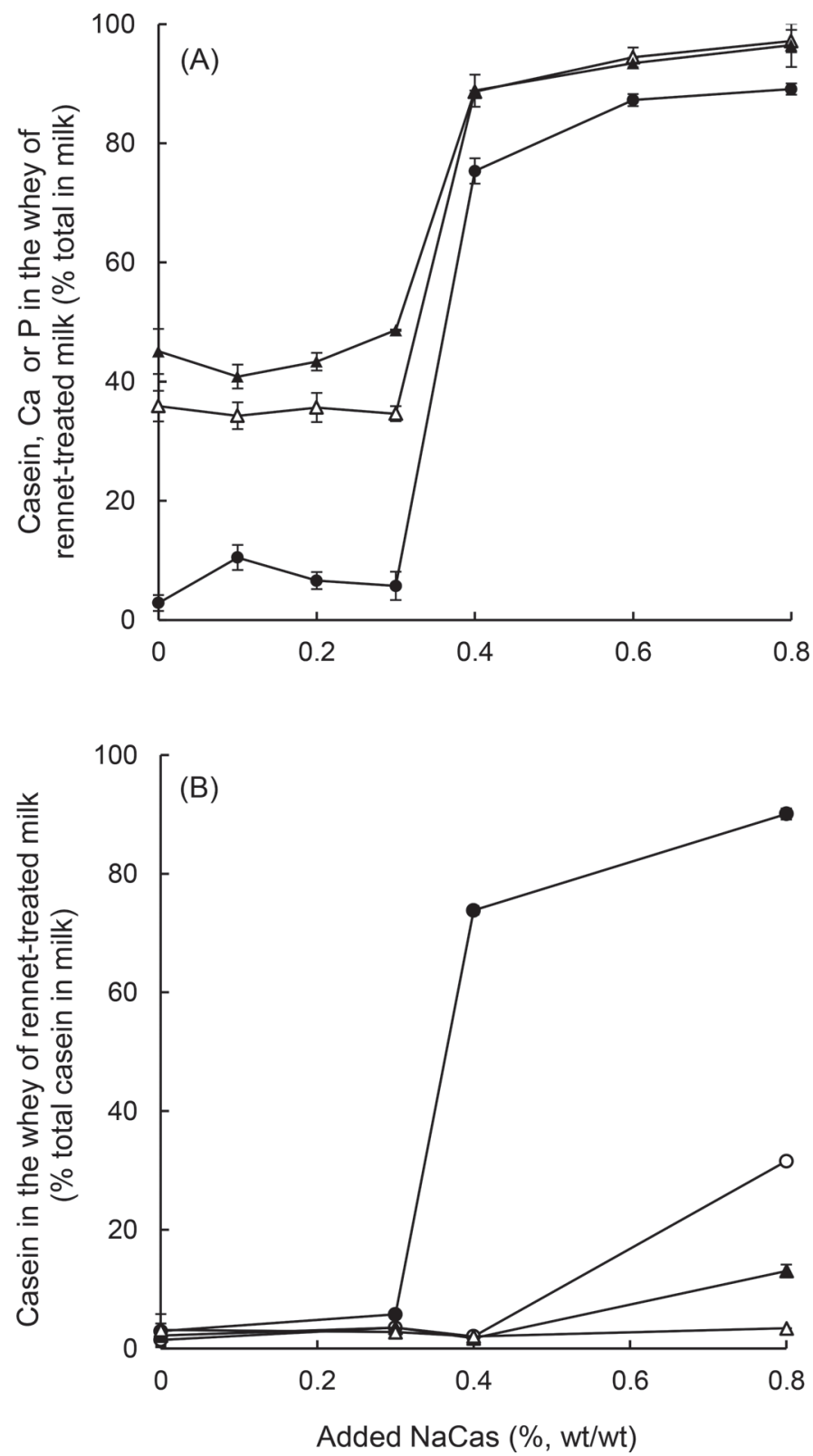

Figure 5. Effect of varying the level (\%,wt/wt) of added sodium caseinate (NaCas) in fortified milk (4.1\% protein) on the composition of whey obtained on centrifugation of the rennet-treated milk: (A) concentrations of casein $(\bullet), \mathrm{Ca}(\Delta)$, or $\mathrm{P}(\boldsymbol{\Delta})$ in the whey (serum) obtained on centrifugation at $3,000 \times g$; and $(\mathrm{B})$ concentration of casein in the whey obtained on centrifugation at $3,000(\bullet), 12,500(\bigcirc), 30,000$ $(\mathbf{\Lambda})$, or $100,000(\Delta) \times g$. Presented data are the means of duplicate batches of each fortified milk; error bars show SD of the mean. scattering by casein particles; this trend concurs with the reduction in sedimentable casein as a proportion of total casein. Similarly, Thomar and Nicolai (2015) reported an increase in the nonsedimentable casein content of an aqueous dispersion of NPC (1.5\%, wt/wt, protein) on addition of NaCas; the turbidity $(685 \mathrm{~nm})$ of the dispersion decreased proportionally with weight
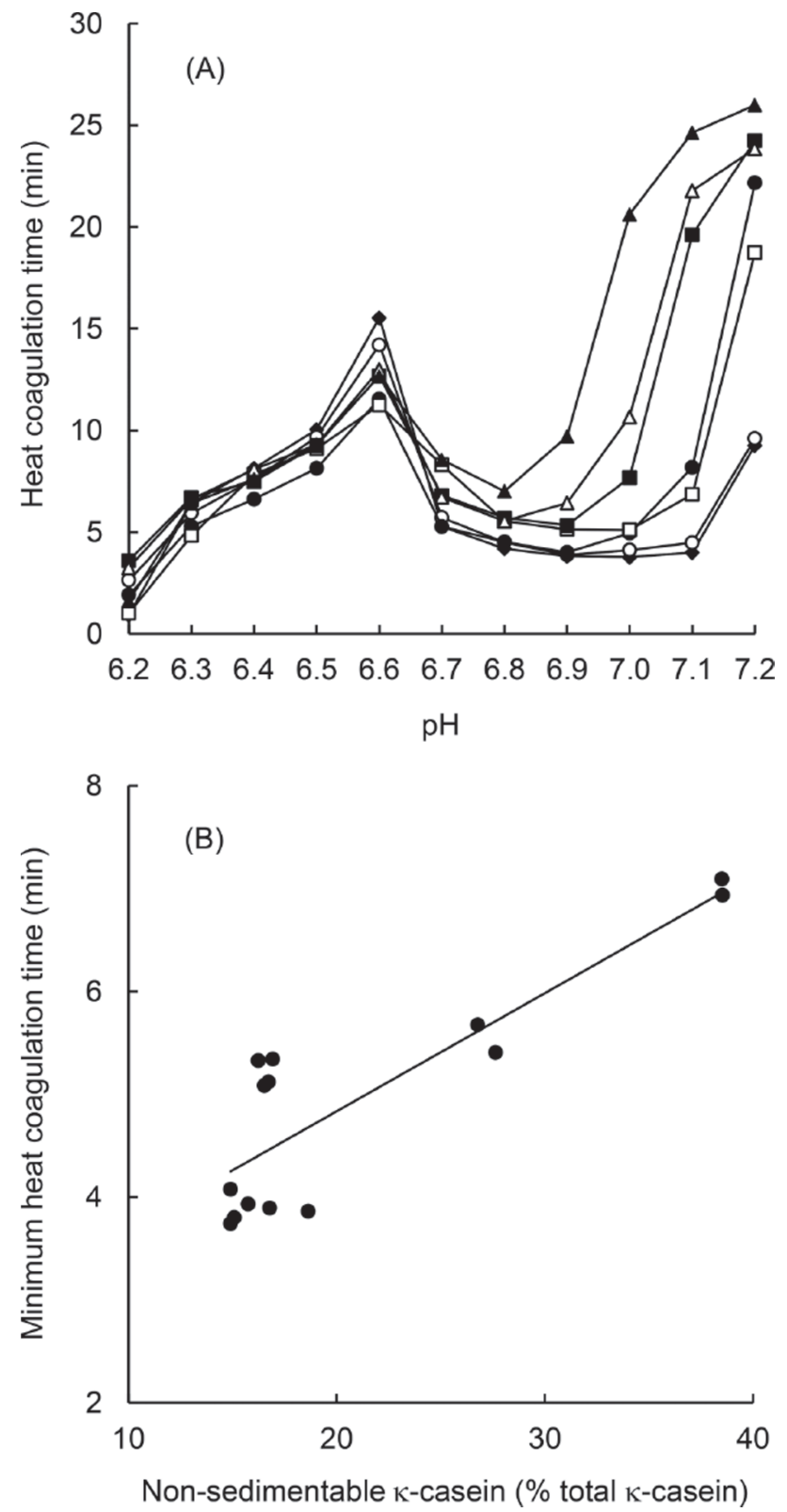

Figure 6. (A) Heat stability of fortified milk (4.1\%, wt/wt, protein) containing different levels $(\%, \mathrm{wt} / \mathrm{wt})$ of sodium caseinate, NaCas: $0.8(\boldsymbol{\Delta}), 0.6(\Delta), 0.4(\boldsymbol{\square}), 0.3(\square), 0.2(\bullet), 0.1(\bigcirc)$, or $0(\diamond)$; presented data show the means of duplicate batches of each fortified milk. (B) Minimum heat coagulation time of fortified milk samples (at $\mathrm{pH}>6.6$ ) as a function of nonsedimentable $\kappa-\mathrm{CN}$ content (\% total $\kappa$-CN in milk). Presented data show values of duplicate batches of 7 fortified milk samples with added NaCas levels ranging from 0 to $0.8 \%$. 

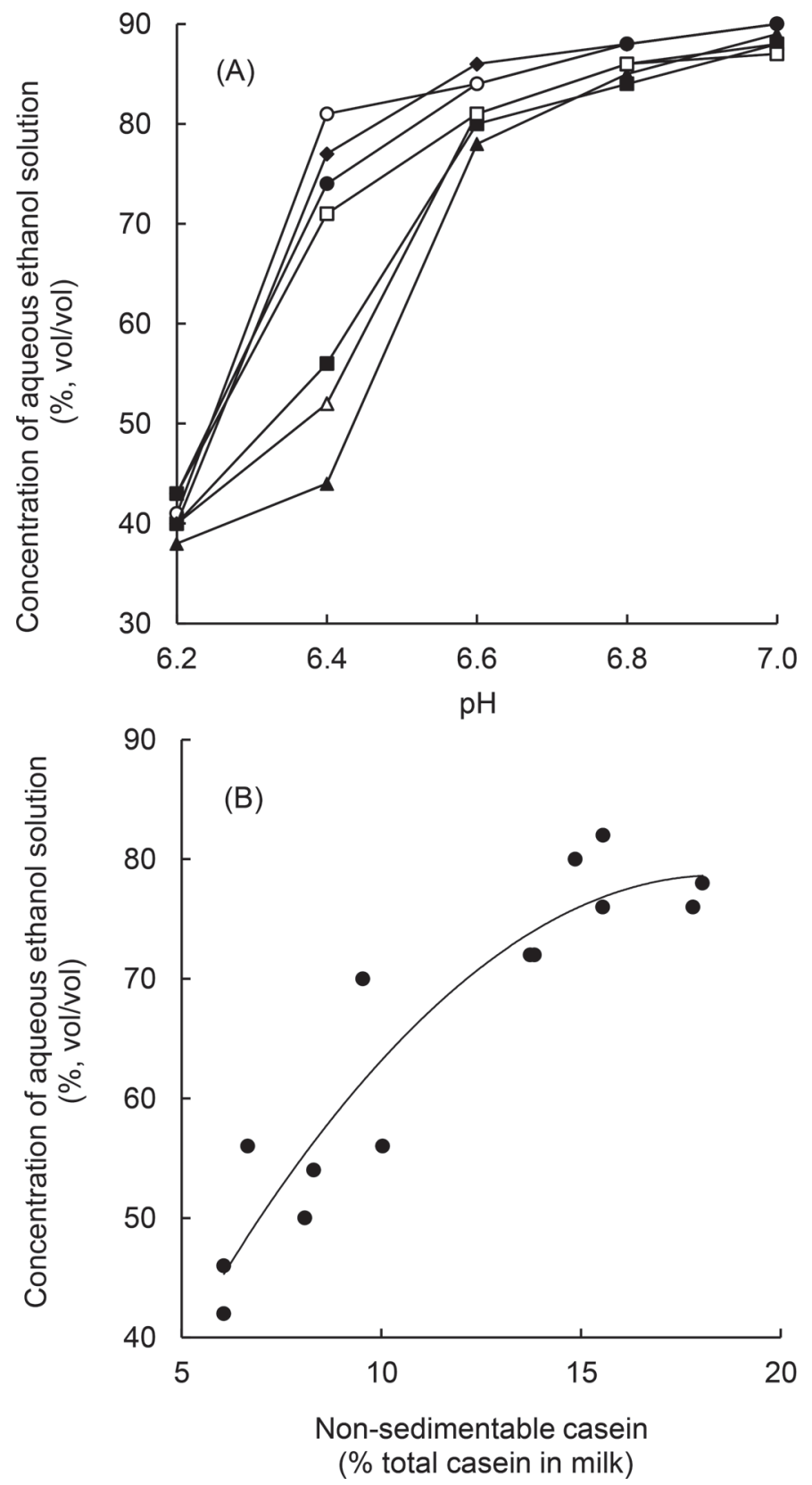

Figure 7. (A) Concentration of ethanol required to induce flocculation of fortified milk samples $(4.1 \%$, wt/wt, protein) containing different levels (\%, wt/wt) of added sodium caseinate, NaCas: $0(\mathbf{\Lambda})$, $0.1(\Delta), 0.2(\mathbf{\square}), 0.3(\square), 0.4(\bullet), 0.6(\bigcirc)$, or $0.8(\bullet)$; presented values are the means of duplicate batches of each fortified milk. (B) Ethanol stability of the fortified milk samples at $\mathrm{pH} 6.4$ as a function of nonsedimentable casein content (\% total casein in milk); presented data show values of duplicate batches of 7 fortified milk samples with added NaCas ranging from 0 to $0.8 \%$ (wt/wt).

fraction of NaCas added. The authors postulated that added NaCas behaved essentially as a Ca-chelating salt, which caused dissociation of the casein micelles in the NPC. Earlier, Parker et al. (2005) found that the level of nonsedimentable casein in reconstituted skim milk, to which NaCas was added, increased as the level of added NaCas was increased from 0.0 to $1.0 \%$ (wt/ wt), but decreased on heating the milk to $80^{\circ} \mathrm{C}$ for 30 min. The authors concluded that $\mathrm{NaCas}$ added to skim milk remained nonsedimentable in the form of soluble complexes (not as sedimentable casein micelle-like particles), which on heating to $80^{\circ} \mathrm{C}$ become largely associated with the casein micelle, probably by binding with the surface layer of $\kappa-\mathrm{CN}$. The current results showed that the increase in nonsedimentable casein on addition of NaCas to skim milk was less than the value expected, had all the added NaCas become nonsedimentable, for example, an increase of $0.42 \%$ (wt/wt) on addition of $0.8 \%$ (wt/wt) NaCas. The results suggest that some of the NaCas added to the skim milk $(0.8 \%$, wt/wt) may have associated with the native casein micelles without altering their mean size (z-average), whereas the remainder, which increases with level of NaCas added, remained nonsedimentable in the ultracentrifugate. It is also possible that some of added $\mathrm{NaCas}$ forms into sub-micellar-type particles (e.g., $<10 \mathrm{~nm}$ diameter) by self-assembly of mono-molecules of NaCas in the presence of serum Ca. Pitkowski et al. (2009) reported that casein which remained nonsedimentable on centrifugation $(56,000 \times g$ for $90 \mathrm{~min}$ at room temperature $)$ of aqueous solutions of $\mathrm{NaCas}$, with different levels of added $\mathrm{CaCl}_{2}$, was organized into small clusters (aggregates) with a radius of $\sim 12 \mathrm{~nm}$ containing $\sim 15$ casein molecules.

The addition of NaCas at $\geq 0.4 \%$ (wt/wt) to skim milk resulted in failure of the milk to undergo rennet-induced gelation. Gaygadzhiev et al. (2012) made a similar observation and hypothesized that the addition of NaCas to skim milk impaired rennet gelation by adsorbing at the interface of the casein micelle and enhancing steric and electrostatic repulsion between para-casein micelles. Our results showed that the level of $12 \%$ (wt/ vol) TCA-SN in fortified milks with different levels of added NaCas (0 to $0.8 \%$ wt/wt) was similar and, therefore, suggest that the rate and extent of hydrolysis of the caseino-macropeptide from the $\kappa$-casein was not a causative factor for the deterioration in rennet gelation as the level of added NaCas increased. This adverse effect of NaCas at $\geq 0.4 \%$ (wt/wt) on rennet-induced gelation may be partly associated with the reduction in $\left[\mathrm{Ca}^{2+}\right]$, and additionally with the decrease in ratio of sedimentable Ca-to-casein at higher levels (0.6 to $0.8 \%$ wt/wt) of added NaCas (Singh et al., 1988). However, the increase in nonsedimentable casein in the milk is also likely to be a contributory factor to the negative effect of NaCas on rennet gelation, as confirmed by the milky appearance and the high proportion of total casein $(\sim 90 \%)$ and $\mathrm{Ca}(98 \%)$ that remained soluble on centrifugation of the rennet-treated milk with $\geq 0.4 \%$ 
$($ wt/wt) NaCas at 3,000 $\times g$. The current results obtained on centrifugation of rennet-treated milk with added NaCas $\geq 0.4 \%$ (wt/wt) suggest that nonsedimentable casein on hydrolysis by chymosin forms into small aggregates that remain soluble (in suspension at low $g$-force, e.g., $3,000 \times g$ ) but sediment increasingly as centrifugation force is gradually increased to 100,000 $\times g$. It is likely that these soluble floating aggregates physically come between and impede, or block, the aggregation of the rennet-altered para-casein micelles (present in the skim milk), and thereby impair their ability to cohere into a continuous gel network.

The addition of NaCas reduced heat stability of the fortified milk at $\mathrm{pH} \leq 6.6$ ( $\mathrm{pH}$ of maximum stability) and increased stability at $\mathrm{pH} 6.8$ to 7.2 ( $\mathrm{pH}$ region of minimum stability), with the effect becoming more pronounced with level of NaCas added. The enhanced heat stability at the higher $\mathrm{pH}$ values concurs with the results of Cho and Singh (1999), who found that the heat stability of milk-fat emulsions $(\sim 2 \%$, wt/wt, protein) in the $\mathrm{pH}$ range 6.4 to 7.1 at $140^{\circ} \mathrm{C}$ was significantly higher when the emulsions were stabilized with NaCas instead of SMP. The influence of NaCas on heat stability at $\mathrm{pH} 6.8$ to 7.2 is likely to be associated with the interactive effects of its relatively low levels of total $\mathrm{Ca},\left[\mathrm{Ca}^{2+}\right]$, sedimentable $\mathrm{Ca}$, lactose and NPN (Table 2; O'Connell and Fox, 2003; Huppertz, 2016). The heat stability of fortified milk is likely to be enhanced on increasing the level of added $\mathrm{NaCas}$ owing to the commensurate reductions in the contents of lactose (Berg and van Boekel, 1994), total Ca (Sikand et al., 2010), $\left[\mathrm{Ca}^{2+}\right]$ (Huppertz, 2016), and whey protein-to-casein ratio (O'Connell and Fox, 2003). Simultaneously, heat stability is likely to be attenuated by the reduction in NPN, and hence, urea (Muir and Sweetsur, 1977) and by the increase in nonsedimentable $\kappa-\mathrm{CN}$ (O'Connell and Fox, 2003).

It is generally considered that the minimum in the heat stability curve of bovine milk is due to the dissociation of $\kappa-\mathrm{CN}$ from the micelle to the serum where it forms soluble complexes with $\beta$-LG, and possibly other whey proteins, via sulfhydryl-disulfide interchange in the serum (Donato and Guyomarc'h, 2009). The resultant $\mathrm{k}$-CN-depleted micelle is more susceptible to Ca-, heat-, and ethanol-induced aggregation (Singh and Fox, 1986). However, the current study indicated a positive correlation between minimum heat coagulation time (Figure 6B) and nonsedimentable $\mathrm{k}-\mathrm{CN}$ (as a proportion of total $\kappa-\mathrm{CN}$ in the fortified milk), which increased from $\sim 15$ to $40 \%$ as NaCas was increased from 0 to $0.8 \%$ (wt/wt); a similar relationship was found between nonsedimentable $\kappa-\mathrm{CN}$ and heat coagulation time at $\mathrm{pH} 6.8,6.9$, or 7.0 with the effect increasing with $\mathrm{pH}$. This anomaly probably reflects again the interactive contribution of different factors to heat stability of the fortified milk. Hence, the expected decrease in heat stability with increasing depletion of micellar $\kappa-\mathrm{CN}$ (O'Connell and Fox, 2003), upon increasing added NaCas, may be more than offset by the positive effects of the concomitant reduction in lactose, $\left[\mathrm{Ca}^{2+}\right]$, total $\mathrm{Ca}$, and whey protein-to-casein ratio.

The increase in ethanol stability with $\mathrm{pH}$ concurs with trends from other studies (Mohammed and Fox, 1986). The positive effect of NaCas on ethanol stability at $\mathrm{pH} 6.4$ is likely to be associated with the reductions in sedimentable casein, $\mathrm{Ca}$ and $\left[\mathrm{Ca}^{2+}\right]$ (Horne and Parker, 1981; Mohammed and Fox, 1986; Horne and Muir, 1990), and lactose content (Lin et al., 2016). However, why such an effect would occur at pH 6.4 only is unclear.

\section{CONCLUSIONS}

The rennet gelation, heat stability, and ethanol stability characteristics of protein-fortified skim milk $(4.1 \%$, wt/wt, protein) were significantly affected by the weight ratio of SMP to NaCas in the protein blend used in fortification. These effects coincided with a change in the ratios of sedimentable-to-nonsedimentable casein and $\mathrm{Ca}$, as influenced by the differences in the $\mathrm{Ca}$ and $\mathrm{P}$ contents between NaCas and SMP. Hence, a low degree of mineralization and Ca-to-P ratio would be conducive to the formation of more heat- and ethanol-stable beverages, but would be detrimental to rennet-induced gelation of recombined milk.

\section{ACKNOWLEDGMENTS}

This work was supported Dairy Levy Trust CoOperative Society Limited (Dublin, Ireland).

\section{REFERENCES}

Agarwal, S., R. L. W. Beausire, S. Patel, and H. Patel. 2015. Innovative uses of milk protein concentrates in product development. J. Food Sci. 80(Suppl. 1):A23-A29.

Berg, H. E., and M. A. J. S. van Boekel. 1994. Degradation of lactose during heating of milk. 1. Reaction pathways. Neth. Milk Dairy J. 48:157-175.

Carr, A., and M. Golding. 2016. Functional milk proteins production and utilization: Casein-based ingredients. Pages 35-66 in Advanced Dairy Chemistry Vol. B: Proteins: Applied Aspects, 4th ed. P. L. H. McSweeney and J. A. O'Mahony, ed. Springer Science+Business Media, New York, NY.

Cho, Y. H., and H. Singh. 1999. Modification of the properties of recombined milk by fat globule surface manipulation. Pages 101-107 in Proceedings of International Dairy Federation Symposium on Recombined Milk and Milk Products, Penang, Malaysia. International Dairy Federation, Brussels, Belgium.

Donato, L., and F. Guyomarc'h. 2009. Formation and properties of the whey protein/ $\kappa$-casein complexes in heated skim milk-A review. Dairy Sci. Technol. 89:3-29. 
Fox, P. F. 1969. Effect of cold-ageing on the rennet-coagulation time of milk. Isr. J. Agric. Res. 8:175-182.

Gaygadzhiev, Z., V. Massel, M. Alexander, and M. Corredig. 2012. Addition of sodium caseinate to skim milk inhibits rennet-induced aggregation of casein micelles. Food Hydrocoll. 26:405-411.

Gilles, J., and R. C. Lawrence. 1982. The manufacture of cheese and other fermented products from recombined milk. Pages 111-117 in Proceedings of International Dairy Federation Seminar on Recombination of Milk and Milk Products, Singapore. International Dairy Federation, Brussels, Belgium.

Glantz, M., T. G. Devold, G. E. Begarud, H. Lindmark-Månsson, H. Stålhammar, and M. Paulsson. 2010. Importance of casein micelle size and milk composition for milk gelation. J. Dairy Sci. 93:1444-1451

Guinee, T. P., B. T. O'Kennedy, and P. M. Kelly. 2006. Effect of milk protein standardization using different methods on the composition and yields of Cheddar cheese. J. Dairy Sci. 89:468-482.

Hindle, E. J., and J. V. Wheelock. 1970. The primary phase of rennin action in heat-sterilized milk. J. Dairy Res. 37:389-396.

Holt, C. and D. D. Muir. 1978. Natural variations in the average size of bovine casein micelles II. Milk samples from creamery bulk silos in south west Scotland. J. Dairy Res. 45:347-353.

Horne, D. S., and D. D. Muir. 1990. Alcohol and heat stability of milk protein. J. Dairy Sci. 73:3613-3626.

Horne, D. S., and T. G. Parker. 1981. Factors affecting the ethanol stability of bovine milk. II. The origin of the $\mathrm{pH}$ transition. J. Dairy Res. 48:285-291.

Huppertz, T. 2016. Heat stability of milk. Pages 179-196 in Advanced Dairy Chemistry: Volume 1B Proteins: Applied Aspects. 4th ed. P. L. H. McSweeney, and J. A. O'Mahony ed. Springer-Science + Business Media, New York, NY.

International Dairy Federation. 2001a. Milk-Determination of nitrogen content-Part 1: Kjeldahl method. IDF, Brussels, Belgium.

International Dairy Federation. 2001b. Milk-Determination of nitrogen content-Part 4: Determination of non-protein-nitrogen content. IDF, Brussels, Belgium.

International Dairy Federation. 2006. Milk-Determination of total phosphorus content-Method using molecular absorption spectrometry. IDF, Brussels, Belgium.

International Dairy Federation. 2007. Milk and milk products-Determination of calcium, sodium, potassium and magnesium contentsAtomic absorption spectrometric method. IDF, Brussels, Belgium.

Jenness, R., and J. Koops. 1962. Preparation and properties of a salt solution which simulates milk ultrafiltrate. Neth. Milk Dairy J. $16: 153-164$.

Lagrange, V., D. Whitsett, and C. Burris. 2015. Global market for dairy proteins. J. Food Sci. 80(Suppl. 1):A16-A22.

Lin, Y., A. L. Kelly, J. A. O'Mahony, and T. P. Guinee. 2016. Fortification of milk protein content with different dairy protein powders alters its compositional, rennet gelation, heat stability and ethanol stability characteristics. Int. Dairy J. 61:220-227.

McSweeney, S., J. O'Regan, and D. O'Callaghan. 2013. Nutritional formulae for infants and young children. Pages 458-476 in Milk and Dairy Products in Human Nutrition: Production, Composition and Health. Y. W. Park and G. F.W. Haenlein, ed. John Wiley \& Sons Ltd., Chichester, UK.

Mohammed, K. S., and P. F. Fox. 1986. Heat and alcohol-induced coagulation of casein micelles. Int. J. Food Sci. Technol. 10:47-55.

Muir, D. D. 1988. Manufacture of cream liqueurs. Dairy Ind. Int. $53: 25-27$.

Muir, D. D., and A. W. M. Sweetsur. 1977. Effect of urea on the heat coagulation of the caseinate complex in skim-milk. J. Dairy Res. 44:249-257.

Nair, P. K., and M. Corredig. 2015. Rennet-induced gelation of concentrated milk in the presence of sodium caseinate: Differences between milk concentration using ultrafiltration and osmotic stressing. J. Dairy Sci. 98:27-36.

O'Connell, J. E., and P. F. Fox. 2000. The two-stage coagulation of milk proteins in the minimum of the heat coagulation time-pH profile of milk: Effect of casein micelle size. J. Dairy Sci. 83:378-386.

O'Connell, J. E., and P. F. Fox. 2003. Heat-induced coagulation of milk. Pages 879-948 in Advanced Dairy Chemistry Volume 1B: Proteins, 3rd ed. P. F. Fox and P. L. H. McSweeney, ed. Kluwer Academic/Plenum Publishers, New York, NY.

O'Kennedy, B. T., M. Cribbin, and P. M. Kelly. 2001. Stability of sodium caseinate to ethanol. Milchwissenschaft 56:680-683.

Parker, E. A., L. Donato, and D. G. Dalgleish. 2005. Effects of added sodium caseinate on the formation of particles in heated milk. J. Agric. Food Chem. 53:8265-8272.

Pitkowski, A., T. Nicolai, and D. Durand. 2009. Stability of caseinate solutions in the presence of calcium. Food Hydrocoll. 23:1164-1168.

SAS Institute Inc. 2011. SAS User's Guide: Statistics. Version 9.3 ed. SAS Institute Inc., Cary, NC.

Sikand, V., P. S. Tong, and J. Walker. 2010. Heat stability of reconstituted, protein-standardized skim milk powders. J. Dairy Sci 93:5561-5571

Singh, H., and P. F. Fox. 1986. Heat stability of milk: Further studies on the $\mathrm{pH}$-dependent dissociation of micellar $\kappa$-casein. J. Dairy Res. 53:237-248.

Singh, H., S. I. Shalabi, P. F. Fox, A. Flynn, and A. Barry. 1988. Rennet coagulation of heated milk: Influence of $\mathrm{pH}$ adjustment before or after heating. J. Dairy Res. 55:205-215.

Thomar, P., and T. Nicolai. 2015. Dissociation of native casein micelles induced by sodium caseinate. Food Hydrocoll. 49:224-231.

Visser, S., C. J. Slangen, and H. S. Rollema. 1991. Phenotyping of bovine milk proteins by reversed-phase high-performance liquid chromatography. J. Chromatogr. 548:361-370. 